\title{
PRIPRAVNIŠTVO - PREDPIS ALI POTREBA
}

$\mathrm{R}$ odsev spoznanj in izkušenj, ki sem si jih nabral v zadnjih dvajsetih letih. Tako ali drugače se srečujem $\mathrm{z}$ različnimi problemi pripravništva in iz različnih zornih kotov. $\mathrm{Na}$ seminarjih za mentorje, $v$ pogovorih $\mathrm{z}$ ljudmi, ki delajo $\mathrm{v}$ kadrovskih in izobraževalnih dejavnostih, celo $\mathrm{v}$ pogovorih $\mathrm{z}$ ljudmi, ki se ukvarjajo s pravicami iz dela, se pojavljajo neposredna ali manj neposredna vprašanja o pomenu in funkciji pripravništva. Nekdo, ki reče (mentor): »Jaz svojega znanja ne mislim razdajati, težko sem ga dobil «,

Funkcija

priprauništva je razvoj

specifičnich spretnosti

za določeno delo. ni preveč dober mentor, drugi meni, da s pripravništvom podpiramo izobraževalni sistem, ki nalaga del procesa izobraževanja na naša pleča, tretji pa: »Tudi to (pravno) oviro bomo že nekako preskočili«, četrti razmišlja o tem, da izobraževanje na zalogo nima smisla, ker ponuja šolski sistem več kadrov, kot jih potrebujemo. Spominjam se direktorja gradbenega podjetja, ki je pred nekaj meseci dejal: » Vi (šolniki) nam dajte kadre, ki so takoj uporabni in znajo delati. Mi nimamo časa za nobeno obliko dodatnega izobraževanja v delovnem procesu! « Skratka, negativnih mnenj, stališč in seveda izvedb je več kot dovolj. In vsi imajo prav, vsak ima pravico do svojega mnenja, hkrati pa nimajo prav. Vse je odvisno od zornega kota, kako gledaš na zadevo. V tem sestavku želim pojasniti svoje poglede in stališča, ki so lahko iztočnica za začetek polemičnih razprav.

\section{PRIPRAVNIŠTVO - ZAPUŠČINA USMERJENEGA IZOBRAŽEVANJA?}

Včasih imam občutek, da je pripravništvo »izmislek « usmerjenega izobraževanja, ki kot tako ne spada $v$ današnji čas. $V$ tem je le kanček resnice. Res je namreč, da so izobraževalni programi, zlasti programi poklicnih šol srednjega izobraževanja $\mathrm{v}$ devetdesetih letih, vsebovali premalo praktičnih vsebin, ki jih je bilo treba nadomestiti med pripravništvom. $S$ tem je šolski sistem tudi načrtno prevalil stroške izobraževanja na delovne organizacije oziroma podjetja. Temu so se vehementno upirali zlasti obrtniki, ki so med prvimi dosegli prenovo izobraževalnih programov za obrti z uvajanjem povečanega obsega praktičnega pouka, s čimer so nadomestili (po njihovem mnenju) nekaj odvečnih ur nepotrebne teorije. Res pa je tudi, da pravzaprav nismo bili nikoli povsem zadovoljni s tem, kar nam daje izobraževalni sistem. Odtod tudi težnje po stalnem spreminjanju in dopolnjevanju sistema vzgoje in izobraževanja. Žal ima pri tem vedno prste vmes tudi politika. Tako je bilo svojčas in tako je na žalost tudi danes, morda nekoliko manj kot prej, pa vendar. Morda izvira določen odpor do pripravništva prav iz tega, da je bilo pripravništvo pravna obveznost za delodajalce, za nas pa je znano, da nismo bili nikoli navdušeni nad tem, kar nam je določila ali predpisala država. To je nekoliko povezano z našo zgodovino, ko smo se tako ali drugače izogibali zahtevam tistih, ki so nam krojili usodo. 
$\mathrm{V}$ devetdesetih sta področje pripravništva urejala Zakon o delovnih razmerjih in Pravilnik o pripravnišstvu in strokovnih izpitih pripravnikov $\mathrm{v}$ gospodarstvu. Omenjeni pravilnik, ki ga je v dveh izdajah sprejela Gospodarska zbornica Slovenije, je (zlasti druga izdaja, ki je izšla leta 1983) bil precej nejasen in nedorečen, tako da so strokovnjaki v izobraževalnih centrih in kadrovskoizobraževalnih službah podjetij skušali $\mathrm{v}$ okviru Skupnosti izobraževalnih centrov Slovenije narediti nekaj reda na tem področju. Pripravili so metodologijo za oblikovanje pripravniških programov in sestavili nekaj vzorčnih programov pripravništva. Poleg tega so predlagali tudi vrsto sistemskih rešitev, med drugim:

- kaj je podlaga za pripravniški program (poklic ali delovno mesto);

- čas trajanja pripravništva;

- časovno razmerje med splošnim in posebnim delom programa;

- določila v zvezi z mentorstvom;

- funkcija mentorja;

- časovno razmerje med splošnim in posebnim delom pripravniškega programa;

- organizacija pripravništva in izpitov itd.

Priporočila Skupnosti izobraževalnih centrov Slovenije so sprejela vsa splošna združenja pri Gospodarski zbornici Slovenije. Ne samo to. Vsem združenjem so iz SIC poslali program usposabljanja mentorjev in oblikovane vzorčne pripravniške programe, na podlagi katerih se je kasneje začelo obširno usposabljanje mentorjev. Skupnost je v nekaj letih izvedla s sodelovanjem delavskih oziroma ljudskih univerz več sto seminarjev za mentorje, na katerih so (v seminarskih delavnicah) nastali številni konkretni pripravniški programi.

Področje pripravništva sedaj pravno urejajo Zakon o delovnih razmerjih, Zakon o zaposlovanju in zavarovanju za primer brezposel- nosti ter Splošna kolektivna pogodba za gospodarstvo. Omenjeni akti določajo temeljne statusne zadeve na podlagi delovnega razmerja ter pravice in dolžnosti pripravnika. Mimogrede naj omenim, da si nekateri lobiji na področju zaposlovanja prizadevajo za zmanjševanje pravic pripravnikov, ki po opravljenem pripravništvu niso sklenili delovnega razmerja za nedoločen čas in imajo torej status brezposelne osebe oziroma čakajo na zaposlitev. Razmišljajo o zniževanju »stroškov «, ki temeljiijo na posledicah pripravništva, s čimer bi se v bistvu deloma prenesla socialna skrb na pleča njihovih staršev. Ta zadeva je vsekakor vredna premisleka.

Spremenjeni predpisi v izobraževanju, zlasti Zakon o poklicnem izobraževanju, so prinesli korenite spremembe v izobraževalne programe v razmerju teorija : praksa. Povečan obseg praktičnega dela, zlasti $v$ dualnem sistemu, odpravlia potrebo po dodatnem usposabljanju učencev, ki so uspešno končali triletne programe poklicnih šol.

Pa vendar - spominjam se odličnega orodjarja iz Saturnusa, ki je trdil, da dobimo dobrega orodjarja šele, ko ta osem let trdo dela v poklicu. Kakorkoli že, učenci triletnih programov imajo bržkone dovolj praktičnega znanja vsaj za začetek dela. V Nemčiji na primer opravljajo finalizacijo poklicnega izobraževanja $\mathrm{v}$ medpodjetniških centrih, o katerih pri nas šele razmišljamo. Recimo torej, da so zadeve glede poklicnih šol in njihovih diplomantov deloma urejene.

Postavimo retorično vprašanje, ki je pravzaprav v naslovu tega prispevka. Kaj pa če pripravništvo ne bi bilo pravno urejeno in bi bilo torej »neobvezno«? Ali pripravništva preprosto ne bi organizirali? Skratka, postavlja se vprašanje, ali je pripravništvo zgolj stvar nekega predpisa, ali pomeni dejansko potrebo. Menim, da gre za dejansko potrebo, in to želim v nadaljevanju tudi dokazati. Vprašajmo se:
As 2) 
Ali je mlad človek, ki je uspešno končal srednjo, višjo ali visoko šolo, takoj pripravljen samostojno opravljati delo na določenem delovnem mestu oziroma v konkretnem poklicu?

Če je odgovor na zastavljeno vprašanje pozitiven, potem pripravništva, uvajanja, sta-

Prehod iz šle $v$ suet dela je pogosto težak.

žiranja, ali kakšne druge oblike adaptacije $\mathrm{v}$ delovno okolje ne potrebujemo.

Trdim, da je odgovor na to vprašanje praviloma negativen, zato bom tezo o tem, da je pripravništvo, vsaj za poklice od tehnika navzgor, smotrno in racionalno, utemeljil z:

\section{1. razmerjem med pojimom pokllicna izobrazba - poklic}

Poklici od tehnika navzgor spadajo med poklice širokega profila. To pomeni, da lahko diplomant (sedanje) V. stopnje zahtevnosti in višje šole opravlja celo vrsto poklicev. Na spričevalu oziroma diplomi poklicne ali srednje strokovne šole je napisan naziv poklicne izobrazbe, poklic pa pomeni zaokrožen del delovnega oziroma tehnološkega procesa. Seznam poklicne izobrazbe je naveden $\mathrm{v}$ razpisu vpisa $\mathrm{v}$ srednje ali visoke šole in v dokumentih ministrstva za šolstvo in šport, seznam možnih poklicev, ki pomenijo potrebe delovnega sistema, pa opredeljuje in našteva Standardna klasifikacija poklicev, ki jo je objavil Urad Republike Slovenije za statistiko. Iz tega je razvidno, da lahko na primer strojni tehnik med drugim opravlja naslednje poklice: tehnični preglednik motornih vozil, tehnolog, analitik dela, vodja delovne skupine ali izmene, programer na strojih $\mathrm{CNC}$, upravljalec zahtevnejših strojev, vzdrževalec, komercialist, nabavni referent, itd. Ali lahko opravlja vse našteto (ali še več) takoj po končanem izobraževanju, brez strokovne prilagoditve? O pozitivnem odgovoru nisem povsem prepričan.

\section{2. razmerjem med programi srednjega in visokega šolstva ter potrebami delovnega sistema}

Šolski izobraževalni programi od sedanje V. stopnje navzgor so oblikovani tako, da dajejo učencem zaokroženo znanje za začetek dela v skladu s tipičnimi deli, ki so navedena v nomenklaturi poklica. Zanimivo bi bilo videti seznam tipičnih del $\mathrm{v}$ nomenklaturi poklicev, $v$ našem primeru za strojnega tehnika, in ga primerjati z najmanj petnajstimi poklici (po SKP), ki jih lahko opravlja diplomant srednje šole za strojništvo. Diplomanti so "izdelek « šolskega sistema, za katerega lahko mirno rečemo, da je zelo tog in neelastičen. Poleg tega »krasi« naš šolski sistem neracionalna mreža šol. Edina rešitev za zmanjšanje razlike med "ponudbo « šolskega sistema in potrebami trga dela je $\mathrm{v}$ strokovnem usposabljanju, izpopolnjevanju in strokovni adaptaciji na dela in naloge, ki jih zahteva konkreten poklic. In kaj je pripravništvo drugega kakor programirano in vodeno usposabljanja za opravljanje konkretnega dela oziroma poklica?

$\mathrm{V}$ zadnjem času se veliko govori tudi o integralnem sistemu izobraževanja, ki naj bi omilil opisane razmere. Pred durmi je sprejem Pravilnika o postopku za pridobitev poklicnih kvalifikacij. Zlasti s slednjim bo, v obliki strokovne nadgradnje, mogoče usposabljanje za poklice, ki niso v ponudbi šolskega sistema. Gre za certifikatni sistem, ki ga bo operativno koordiniral Center RS za poklicno izobraževanje $\mathrm{s}$ sodelovanjem obeh zbornic (obrtne in gospodarske) ter 


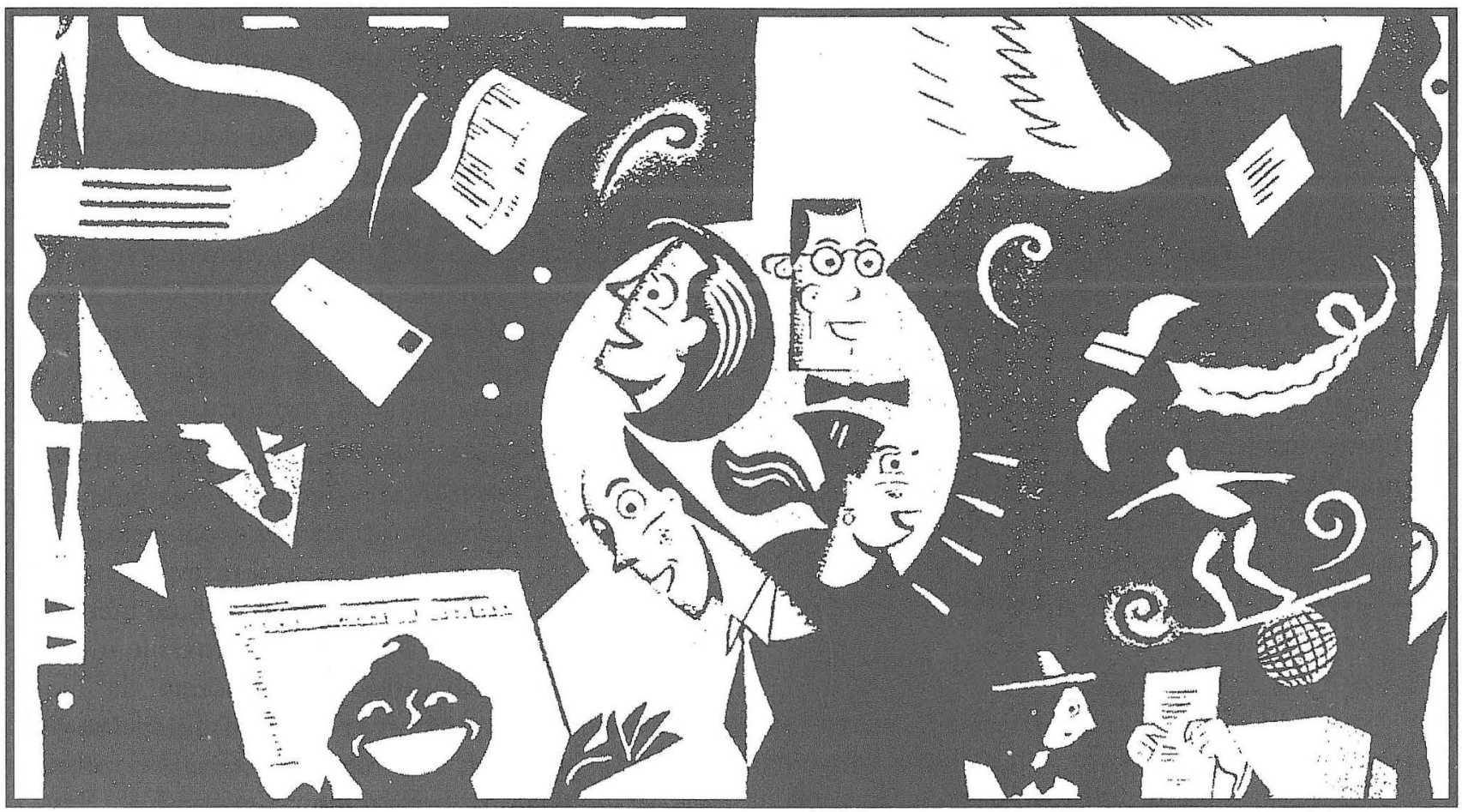

obeh ministrstev (za šolstvo in za delo). Pravni vir navedene informacije je Uradni list RS, št. 69/98, oziroma 53. č člen Zakona o spremembah in dopolnitvah Zakona o zaposlovanju in zavarovanju za primer brezposelnosti.

\section{3. interesi in potrebami podjetja}

Razumljivo je, da potrebuje vsako podjetje dobre kadre na vseh ravneh zahtevnosti dela. Idealno bi bilo, če bi bilo na trgu dela veliko število visoko usposobljenih in takoj uporabljivih kadrov, ki bi ponujali svoje znanje in ustvarjalnost po najnižjih cenah. Žal pa je to daleč od realnosti, zato nam preostanejo le normalne poti in možnosti. In te možnosti gredo le prek usposabljanja in strokovnega izpopolnjevanja lastnih kadrov na vseh ravneh zahtevnosti dela. Eden takšnih načinov je nedvomno usposabljanje pripravnikov. Trdim celo, da je usposabljanje pripravnikov sebično dejanje, kajti njegov cilj je jasen: v razmeroma kratkem času osvežiti delovni potencial podjetja z mladimi ljudmi, polnimi entuziazma in delovne energije. Pripeljati v hišo neizkušenega človeka in od njega zahtevati nemogoče, je milo rečeno ekonomski avanturizem.

Na tem mestu bi rad opisal dva možna primera:

a) Medicina je zahteven petletni študij, ki vključuje tudi dosti prakse. Vprašanje se glasi takole: Ali bi se odločili za srčno operacijo, če bi vas operiral uspešen diplomant medicine brez prakse?

b) Ali bi se odločili za let z letalom, če bi ga upravljal mlad pilot, ki je doslej letel le na simulatorju?

$\mathrm{V}$ obeh primerih gre za zahtevne in odgovorne poklice, pri katerih je po uspešnem študiju predvidena vsaj dveletna praksa, ki se lahko imenuje stažiranje, kopilotiranje, treniranje, pripravništvo, uvajanje ali karsi- 
bodi. Vprašanje nasprotnikom pripravništva: »Pri nas so torej nepomembni, neodgovorni in zelo enostavni poklici in dela $\mathrm{v}$ delovnem procesu?

Izjemno pomembna funkcija $\mathrm{v}$ sistemu usposabljanja, pripravništva, stažiranja, uvajanja v delo, itd. je nedvomno mentorstvo. Menterstvo lahko označimo kot starševstvo y delovnem procesu ... pomeni nadvse odgovorno strokovno, vzgojno in organizacijsko nalogo. Mentorstvo je začetek voditelistva, zato je izbira mentorja izjemno zahtevna naloga. Naloge mentorja segajo od neposredne strokovne pomoči in opore pripravniku do skrbi za njegov razvoj in napredek. Zato za mentorje izbiramo odlične strokovnjake, s čutom za odgovornost, ljudi, ki jih bodo pripravniki pomnili do konca življenja.

\section{SIKLEP}

Upam, da sem utemeljil tezo o potrebah organiziranega, usmerjenega, planiranega in dobro izvedenega usposabljanja mladih, ki so končali izobraževanje v srednjih strokovnih, na višjih in visokih šolah. Ne glede na to, kako je področje usposabljanja opredeljeno $\mathrm{v}$ predpisih, velja, da interes podjetja narekuje načrtno adaptiranje mladih delavcev zahtevam organizacije, tehnologije, sistema informacij, razvoja, proizvodnje, kakovosti in ekonomskih ter drugih učinkov proizvodnje. Ideja se ujema $\mathrm{z}$ načelom, da je vsako delo mnogo uspešnejše, če ga prej kakovostno pripravimo.
Kakovostno in ekonomično usposabljanje za konkretno delo je možno le $\mathrm{v}$ avtentičnem delovnem okolju, torej v konkretni tovarni, obratu, oddelku ali delavnici. Tu imamo na voljo vse potrebne tehnične, organizacijske in kadrovske razmere za kakovostno usposabljanje. In pripravništvo je v bistvu priprava na samostojno delo. Temelji na dobrem programu, ustrezni organizaciji izvajanja procesa usposabljanja in na dobrem, motiviranem mentorju.

Ker traja pripravništvo neprimerno krajši čas kot izobraževanje do prvega poklica, ga lahko štejemo, gledano z ekonomskega vidika, med kratkoročne izobraževalne naložbe. Že samo to dejstvo dovolj tehtno utemeljuje potrebo po smotrnem oblikovanju in izvedbi pripravništva. Lahko rečemo, da imamo pravzaprav prvi priložnost dobiti nazaj del sredstev, vloženih v pripravnikov izobraževalni proces. Pri tem se moramo vendar zavedati, da naš izobraževalni sistem, vsaj na višjih ravneh izobraževanja, ne daje neposrednega znanja in usposobljenosti, ki ga je možno takoj uporabiti $\mathrm{v}$ proizvodnem ali poslovnem procesu. $\mathrm{V}$ pripravnika je treba investirati še nekaj dodatnih sredstev in energije in šele potem lahko pričakujemo želene rezultate. Investicije $\mathrm{v}$ znanje so prav gotovo najdonosnejše. Prepričan sem, da se o tem vsi strinjamo. 